\title{
Qualitative and Quantitative Lymphoscintigraphy in the Evaluation of Lower Limbs Lymphedema
}

\author{
Roberta Maria Dalia ${ }^{2 *}$, Gláucia Ribeiro P. Martins $^{2}$, Rodolfo Barbosa ${ }^{2}$, Carla Flávia de \\ Lima $^{1}$ and Cristiano Ferrari Siqueira ${ }^{1}$ \\ ${ }^{1}$ Ecograf Medicina Nuclear; ${ }^{2}$ União Educacional do Vale do Aço; Domingos Vieira, 589; Santa Efigênia; Belo \\ Horizonte - MG - Brasil
}

\begin{abstract}
The purpose of this study was to prove the efficiency of qualitative and quantitative lymphoscintigraphy in the diagnosis of the lower extremity lymphedema. Seventy-seven patients had been studied, most of then (85.7\%) were female. Patients' ages ranged from 18 to 82 years. All patients underwent a bilateral lymphoscintigraphy. Images were recorded with a dual-detector instrument in the whole-body scanning mode. Feet and inguinal static views were acquired within 15 minutes and three hours after radiopharmaceutical injection. Two nuclear doctors evaluated the lymphoscintigrams qualitatively. Quantitative studies of the radiopharmaceutical absorption and the lymph node chain uptake were also obtained. Of the 154 evaluated members, $21.44 \%(n=33)$ were classified as normal, $61.68 \%(n=95)$ as mildly altered and $16.88 \%(n=26)$ much altered. Quantitation of lymphatic chain uptake may be a more sensitive approach to the diagnosis of lymphatic impairment than the qualitative analysis.
\end{abstract}

Key words: Lymphedema, lymphoscintigraphy, lower limbs, dextran, radiopharmaceutical.

\section{INTRODUCTION}

Lymphedema can be defined as the tissue fluid accumulation that arises as a consequence of impaired lymphatic drainage. There are effective therapies for lymphedema that can be implemented, particularly after the disorder is characterized with lymphoscintigraphy (Marcks, 1997).

Lymphedema can be surprisingly difficult to diagnose, especially in its early stages. Therapy is often delayed without a proper diagnosis. Early treatment often results in rapid clinical improvement and prevents progression to the chronic phase of the disease (Pitta, 2003).
Lymphoscintigraphy offers an objective and reliable approach to diagnose and characterize the severity of lymphedema. Lymphoscintigraphy can be used to differentiate lymphatic from venous edema, myxedema, lipedema, or other etiology. It is also used to identify sentinel nodes in melanoma and breast cancer (Ter, 1993).

Injection of radiolabeled tracers with subsequent gamma camera monitoring has been used to study the lymphatic system since the 1950s. The method has largely replaced the more invasive technique of lymphangiography. The protocol for lymphoscintigraphy is not standardized and differs among diagnostic centers. Differences include the choice of radiotracer, the type and site of injection, the use of dynamic and static acquisitions, and the acquisition times (Szuba, 2003).

\footnotetext{
${ }^{*}$ Author for correspondence
} 
Criteria for lymphatic dysfunction include delay, asymmetric or absent visualization of regional lymph nodes and the presence of "dermal backflow." Additional findings include asymmetric visualization of lymphatic channels, collateral lymphatic channels, interrupted vascular structures, and the deep lymphatic nodes (popliteal lymph nodes) after web space injection in the lower extremities (Andrade, 2003).

Mild lymphedema can be missed by qualitative interpretation. Scoring systems and quantitative analysis have been suggested to enhance diagnostic differentiation in borderline cases (Szuba, 2003). The purpose of this study was to compare the efficiency of the quantitative to that of the qualitative lymphoscintigraphy in the diagnosis of the lymphedema in the lower extremities.

\section{MATERIALS AND METHODS}

A total of 77 patients (66 women, 11 men) were studied. The patients' ages ranged from 18 to 82 years $(54 \pm 14.15$ years old). Lymphoscintigraphy evaluated lymphedema's suspicious of lower extremities. Twenty-one patients had unilateral extremity involvement, and 56 had bilateral involvement, in a total of 154 extremities evaluated. The patients were divided in agreement with gravity discoveries in three groups: normal, mildly altered and much altered lymphoscintigraphy.

Informed consent was obtained from all patients. The interdigital spaces of the lower extremities were first cleaned. A total of $148 \mathrm{MBq}$ of Dextran${ }^{99 \mathrm{~m}} \mathrm{Tc}$ in a volume of $0.4 \mathrm{~mL}$ was injected intradermaly in four equally divided doses in all interdigital spaces bilaterally, using a 27 -gauge needle (Henze, 1982). Care was taken not to puncture small blood vessels by aspirating before injection (Hung, 1995).

Images were recorded with a dual-detector instrument, using high-resolution parallel-hole collimators, with a $20 \%$ window centered on the $140-\mathrm{keV}$ photopeak of ${ }^{99 \mathrm{~m}} \mathrm{Tc}$. Body scan, bilateral injection sites, pelvis and abdomen images were obtained within about 15 minutes of injection and at three hours after tracer administration. ROIs were drawn on injection sites and inguinal nodes to quantify the inguinal lymph node accumulation and the radiopharmaceutical clearance from the injection site.

Two nuclear doctors examined the lymphatic channels caliber, the time of inguinal uptake, the presence of popliteal nodes, the collateral circulation and the "dermal back-flow." Scoring systems were obtained for the analysis of the lymphoscintigraphy (Table 1). According to the lymphangiographic score classification, the lower extremities were considered normal (7-11), mildly altered (12-17) and much altered (18-27).

Table 1- Lymphangiographic score of lymphedema

\begin{tabular}{lccccc}
\hline & $\mathbf{1}$ & $\mathbf{2}$ & $\mathbf{3}$ & $\mathbf{4}$ & $\mathbf{5}$ \\
\hline Time of inguinal uptake & 10 minutes & $10-16$ minutes & $<30$ minutes & 3 hours & Absentee \\
Lymphatic trunks visuali & Well delineated & Partially & Badly delineated & No visualized & - \\
Caliber of trunks & Normal & Decreased & Increased & - & - \\
Dermal reflux & Absent & Distal & Medium & Proximal & - \\
Inguinal nodes uptake & Normal & Increased & Reduced & Absentee & - \\
Hepatic uptake & Normal & Reduced & Absentee & - & - \\
Collateral circulation & Absence & Presence & - & - & - \\
Popliteal nodes uptake & Absence & Presence & - & - & - \\
\hline
\end{tabular}

The quantitative studies of the radiopharmaceutical clearance from the injection site (RC) and the inguinal node uptake (NU) were obtained for the following equations:

$$
\mathrm{RC}=\frac{[\mathrm{IIS} \times 0.71]-\text { LSI }}{\text { IIS X } 0.71}
$$

$\mathrm{NU}=\underline{\text { Late inguinal node uptake }}$
RC: clearance in injection site;

IIS: initial uptake in the injection site;

LSI: late uptake in the injection site;

Technetium's correction factor: 0.71 ;

NU: inguinal node uptake.

The patients' collected data (qualitative and quantitative) were introduced into the Epinfo 6.0 
program, the averages, standard deviations, and significance values $(p)$ being obtained.

\section{RESULTS AND DISCUSSION}

Of the 154 members evaluated for the qualitative lymphoscintigraphy, $21.44 \%(\mathrm{n}=33)$ were classified as normal, 61.68\% $(\mathrm{n}=95)$ mildly altered and $16.88 \%(n=26)$ much altered. Among the patients with accentuated lymphedema, the factors of risk of larger prevalence were sedentarism $(78.8 \%)$, family history $(33.3 \%)$ and obesity $(45.4 \%)$.
Abdel-Dayem (1998) observed that some disorders can cause primary and secondary lymphedema. The frequency of those diseases in the studied patients is presented in Table 2. The more rapid absorption of ${ }^{99 \mathrm{~m}} \mathrm{Tc}$-Dextran allowed shorter study times, provided better visualization of lymphatic trunks, and may be considered preferable for quantitative analyses (Henze, 1982).

The lower incidence of lymphoscintilographic alterations in the normal patients can be seen in Table 3. The mild alterations group presented a reduction of lymphatic vein caliber and delay of inguinal node uptake. The serious patients group presented a larger frequency and intensity of alterations in relation to the other groups.

Table 2- Diseases more frequently found in the patients

\begin{tabular}{lccc}
\hline & Normal & Mildly altered & Much altered \\
\hline DVT & $3.03 \%$ & $4.21 \%$ & $9.84 \%$ \\
Venous insufficiency & $25.21 \%$ & $41.52 \%$ & $62.15 \%$ \\
Erysipelas & $3.03 \%$ & $7.36 \%$ & $46.15 \%$ \\
Trauma & $3.09 \%$ & $9.21 \%$ & $18.84 \%$ \\
Cancer & $5.06 \%$ & $7.36 \%$ & $9.84 \%$ \\
\hline
\end{tabular}

Table 3- Lymphangiographic alterations in the patients' groups

\begin{tabular}{lccc}
\hline & Normal & Mild altered & Much altered \\
\hline Inguinal uptake late & 0 & 0 & $26.92 \%$ \\
Lymphatic trunks & 0 & $7.36 \%$ & $34.61 \%$ \\
Caliber of trunks & $20.30 \%$ & $73,68 \%$ & $96.15 \%$ \\
Dermal reflux & 0 & $13.68 \%$ & $42.30 \%$ \\
Inguinal nodes uptake & 3.03 & $30.52 \%$ & $69.23 \%$ \\
Hepatic uptake & 0 & $11.57 \%$ & $46.15 \%$ \\
Popliteal node uptake & $1.09 \%$ & 13.68 & $42.30 \%$ \\
Collateral circulation & $1.03 \%$ & $8.42 \%$ & $26.92 \%$ \\
\hline
\end{tabular}

Dermal reflux attacked $27.9 \%$ of the evaluated members, being an important prognostic sign. Usually its emergence happened in the late images, indicating the extravascular lymphatic transport, secondary to the destruction of the local vessels (Cestari, 1994).

There was no significant difference when the clearance from the injection site was compared in the three groups $(\mathrm{p}=0.1169)$. Szaba $(1998)$ did not discriminate between healthy patients and patients with lymphedema using the clearance from the injection site.

The data described here a were compatible with that of the literature (Szuba, 2003), showing a regional smaller lymph node accumulation of radiotracer, mainly in the strongly altered members $(\mathrm{p}=0.0081)$.

The quantitative and qualitative lymphoscintigraphy were compared, and it was observed that the qualitative interpretation confirmed the diagnosis of lymphedema in $70 \%$ of extremities, whereas quantitative analysis detected abnormal lymphatic function in $85 \%$ of the limbs examined. All cases missed by qualitative interpretation were mild lymphedema.

The quantitative evaluation of the inguinal uptake after three hours and the qualitative 
analysis were good methods for the diagnosis of the lymphedema. The data obtained suggest that the quantitative method may be a more sensitive approach to differentiate normal patients or those with mild lymphedema.

\section{RESUMO}

O objetivo do estudo foi comprovar a eficiência da linfocintilografia qualitativa e quantitativa no diagnóstico e na classificação da gravidade do linfedema de membros inferiores. Foram estudados 77 pacientes, sendo $66(85,7 \%)$ do sexo feminino, na faixa etária entre 18 e 82 anos. Todos os pacientes foram submetidos a uma linfocintilografia bilateral, com um equipamento de dois detectores, na qual se adquiriu imagens dos pés, da região inguinal e uma varredura dos membros, após 15 minutos e três horas da injeção do radiofármaco. Os exames foram avaliados qualitativamente por 2 médicos nucleares. Também foram feitos estudos quantitativos da absorção do radiofármaco e da captação em cadeia inguinal. Dos 154 membros avaliados classificaram-se como normais $21,44 \%(\mathrm{n}=33)$, pouco alterados $61,68 \% \quad(\mathrm{n}=95)$ e muito alterados $16,88 \%$ $(n=26)$. A quantificação da captação da cadeia linfática pode ser um método mais sensível para o diagnóstico do linfedema em relação à análise qualitativa.

\section{REFERENCES}

Abdel-Dayem, H. M.; Siraj, Q. H. and Collier, B. D. (1998), Lymphoscintigrapy. In: Maisey, M. N. (Ed.). Clinical Nuclear Medicine. Londres. pp. 541-552.

Andrade, M. F. C. (2003). Linfedema. In: UNCISAL/ECMAL and LAVA (Ed.). Angiologia e cirurgia vascular: guia ilustrado. Maceió. pp. 16.

Cestari, S. C. P.; Petri, V.; Castiglioni, M. L. V. and Lederman, H. (1994), Linfedema dos membros inferiores: Estudo linfocintilográfico. Rev. Ass. Med. Bras., 40, 93-100.

Marcks, P. (1997), Limphedema: Pathogenesis, Prevention and Treatment. In: Cancer practice. pp. 34-36.

Henze, E.; Schelbert, H. R.; Collins, J. D.; Najafi, A. and Bennet, L. R. (1982), Lymphoscintigraphy with Tc- ${ }^{99 \mathrm{~m}-l}$ labeled dextran. J. Nucl. Medicine, 23, 923-929.

Hung, J. C.; Wiseman, A. G.; Wahner, H. W.; Mullan, B. P.; Taggart, T. R. and Dunn, W. L. (1995), Filtered technetium ${ }^{-99 \mathrm{~m}-}$ sulfur colloid evaluated for lymphoscintigraphy. J. Nucl. Medicine, 36, 1895-1901.

Pitta, G. B. B.; Castro, A. A. and Burihan, E. (2003), Tratamento clínico do linfedema. In: UNCISAL/ECMAL and LAVA (Ed.). Angiologia e cirurgia vascular: guia ilustrado. Maceió. pp. 115.

Szaba, A. and Rockson, S. G. (1998), Lymphedema. In: Vascular Medicine. v. 3. pp.145-156.

Szuba, A.; Shin, W. S.; Strauss, H. W.; Rockson, S. (2003) The third tirculation: radionuclide lymphoscintigraphy in the evaluation of lymphedema. J. Nucl. Medicine, 44, 43-57.

Ter, S. E.; Alavi, A.; Kim, C. K. and Merli, G. (1993), Lymphoscintihgraphy A reliable test for diagnosis of lymphedema. In: Clinical Nuclear Medicine. pp. 646-654. 